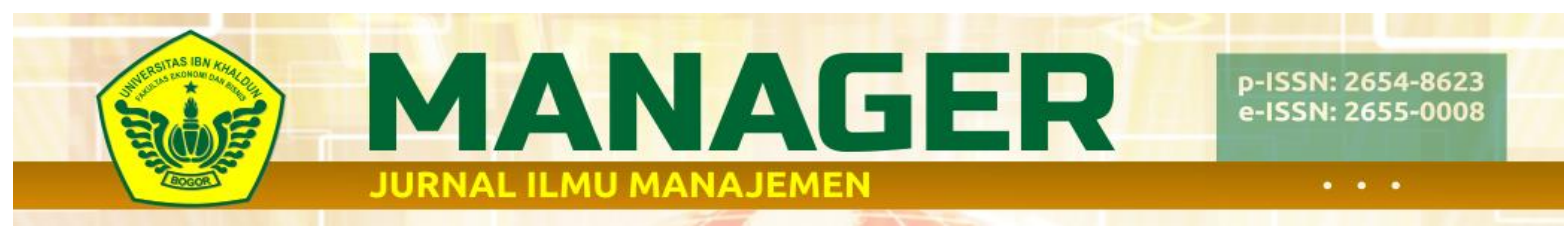

Vol. 3, No. 3, Agustus 2020, Hal 421-432

http://ejournal.uikabogor.ac.id/index.php/Manager/index

\title{
PENGARUH HARGA, ULASAN, DAN TAMPILAN PRODUK TERHADAP KEPUTUSAN PEMBELIAN SECARA ONLINE
}

\author{
Agung Pramono, Achyar Eldine, Leny Muniroh \\ Fakultas Ekonomi dan Bisnis, Universitas Ibn Khaldun Bogor, Indonesia \\ agungpramono1406@gmail.com, achyar@uika-bogor.ac.id, lenymuniroh@uika- \\ bogor.ac.id
}

\begin{abstract}
This research aims to determine the influence of prices, product reviews and the appearance of the product of purchasing decisions online (case studies in custom casing Rendevous Industries products on Tokopedia). This type of research is quantitative and techniques of collecting survey data with the dissemination of online questionnaires. The samples in this study were as much as 96 respondents taken with the technique of sampling purposive.Data Analysis methods use multiple linear regression analyses accompanied by $F$ (simultaneous) tests and $T$ (partial) tests, coefficient of determination and hypothesis testing by using a computer application SPSS 24.0. Test results show that prices, reviews and product views are positively and significantly impacted by online purchase decisions in custom casing Rendevous Industries products in Tokopedia. A very influential factor in the online purchase decision of the custom casing Rendevous Industries Products at Tokopedia is the price.
\end{abstract}

Keywords: price, product reviews, product display, purchase decision.

\begin{abstract}
Abstrak
Penelitian ini bertujuan untuk mengetahui pengaruh harga, ulasan produk dan tampilan produk terhadap keputusan pembelian secara online (Studi kasus pada produk casing custom Rendevous Industries di Tokopedia). Jenis penelitian ini adalah kuantitatif dan teknik pengumpulan data survei dengan penyebaran kuesioner online. Sampel dalam penelitian ini sebanyak 96 responden yang diambil dengan teknik sampling purposive. Metode analisis data menggunakan analisis regresi linier berganda disertai uji $\mathrm{F}$ (simultan) dan uji t (parsial), koefisien determinasi dan uji hipotesis dengan menggunakan aplikasi komputer SPSS 24.0. Hasil pengujian menunjukan bahwa harga, ulasan dan tampilan produk berpengaruh secara positif dan signifikan terhadap keputusan pembelian secara online pada produk casing custom Rendevous Industries di Tokopedia. Faktor yang sangat berpengaruh terhadap keputusan pembelian secara online pada produk casing custom Rendevous Industries di Tokopedia adalah harga.
\end{abstract}

Kata kunci : Harga, Ulasan Produk, Tampilan Produk, Keputusan Pembelian. 


\section{Pendahuluan}

\section{Latar Belakang}

Perkembangan teknologi komunikasi dan informatika semakin dimanfaatkan oleh masyarakat untuk memperoleh atau menyebar informasi. Penggunaan layanan internet telah tersebar di berbagai wilayah di Indonesia dengan total pengguna yang besar, Menurut data statistik yang dikeluarkan oleh internetworldstats.com (2019), Indonesia berada di posisi ke-5 pengguna internet di dunia, dengan total sekitar 143 juta pengguna internet atau sekitar $53 \%$ dari total populasi di Indonesia. Hal ini menunjukan antusias penggunaan internet di Indonesia sangat tinggi dan lebih dari setengah populasi di Indonesia telah memanfaatkan internet.

Selain digunakan untuk memperoleh dan menyebarkan informasi, internet juga digunakan untuk berbagai kebutuhan lainnya, salah satunya adalah jual dan beli atau bisnis secara online. E-Commerce (Ellectronic Commerce) merupakan kegiatan komersial dengan penyebaran penjualan, pembelian, pemasaran barang dan jasa melalui sistem elektronik seperti internet, televisi, atau jaringan komputer lainnya Sinha \& Kim (2012:49). Dengan besarnya populasi penduduk dan penetrasi pengguna internet di Indonesia, mengakibatkan pesatnya perkembangan $e$ commerce di Indonesia presidenri.go.id (2016). Melihat perkembangan teknologi komunikasi dan infomatika, serta pesatnya pertumbuhan pasar $e$-commerce di Indonesia, menarik pelaku

bisnis

untuk mengimplementasikan e-commerce di dalam bisnisnya. Para pelaku bisnis kemudian memanfaatkan keberadaan sejumlah marketplace yang menawarkan tempat pemasaran. Salah satu marketplace terbesar di Indonesia adalah Tokopedia dengan memiliki 4 juta merchants yang menghasilkan lebih dari Rp 1 triliun dari 40 juta produk terjual setiap bulannya (Idris, 2017). Tokopedia memiliki jumlah pengunjung pada triwulan III 2018 mencapai 153,64 juta. Angka tersebut mengalahkan pengunjung e-commerce lainnya seperti Bukalapak, Shopee maupun Lazada (Databoks, 2018).

Seperti marketplace pada umumnya, Tokopedia memberikan fitur pengkategorian produk dalam websitenya, casing dan cover merupakan salah satu sub kategori yang ada di dalam Tokopedia. Indonesia adalah negara dengan populasi lebih dari 265 juta jiwa, dengan tingkat penggunaan handphone yang melebihi populasi penduduk Indonesia, Ini dikarenakan setiap individu bisa memiliki lebih dari 1 handphone. Bisnis casing custom handphone akan tetap berjalan 5-10 tahun mendatang 
dikarenakan handphone telah menjadi bagian dari hidup penduduk modern.

Menurut Prihatna dalam Sudarsono (2017:2), Secara global urutan transaksi yang dilakukan e-commerce yaitu : a). Find it, mencari jenis produk atau barang yang ingin dibeli. b). Explore it, mempelajari dengan baik spesifikasi barang yang akan dibeli. c). Select it, menyimpan barang yang akan dipilih untuk dibeli kedalam shopping cart. d). Buy it, memproses transaksi pembayaran. dan e). Ship it, mengakhiri proses transaksi atau transaksi sudah berhasil kemudian dilakukan proses pengiriman barang.

Pembeli memiliki beberapa pertimbangan sebelum memutuskan untuk membeli produk. Contoh dari pertimbangan-pertimbangan tersebut diantaranya harga, ulasan, dan tampilan produk dalam bertransaksi. Dalam penelitiannya, Shanthi \& Kannaiah (2015:19), menemukan bahwa harga adalah faktor yang paling berpengaruh terhadap Keputusan Pembelian online. Di Tokopedia pembeli dapat melihat harga produk yang dicari, dan harga produk tersebut bisa diurutkan mulai dari yang termurah hingga yang termahal sehingga pembeli dapat dengan mudah menemukan harga yang sesuai dengan keinginanya. Sebelum membeli produk di Tokopedia, pembeli bisa melihat ulasan produk yang telah di berikan dari pembeli sebelumnya. Di Tokopedia pembeli dapat memberikan ulasan produk dengan memberikan ulasan produk dengan memberikan bintang 1-5 (dari buruk hingga sangat baik). Tampilan produk merupakan suatu sarana untuk mempermudah konsumen dalam memilih dan membandingkan produk apa yang akan dibeli. Di dalam tampilan produk sangat diperlukan desain yang bagus, foto yang jelas, dan juga penjelasan mengenai produk itu sendiri. Tentu semua itu akan sangat berpengaruh pada keputusan pembelian.

\section{Metodologi Penelitian}

\section{Populasi dan Sampel}

Menurut Sugiyono (2017:80), Populasi adalah wilayah generalisasi yang terdiri atas: obyek/subyek yang mempunyai kualitas dan karakteristik tertentu yang ditetapkan oleh peneliti untuk dipelajari dan kemudian ditarik kesimpulannya, populasi pada penelitian ini yaitu konsumen yang melakukan pembelian suatu produk yang ditawarkan, oleh karena itu populasi ini adalah populasi yang tidak terbatas karena belum diketahui secara pasti ukuran yang sebenarnya pada konsumen yang melakukan pembelian pada produk yang ditawarkan.

\section{Pengambilan Populasi}

Jumlah populasi yang digunakan oleh penulis sebanyak 2.267 orang yang sudah melalukan transaksi pembelian produk casing custom Rendevous Industries 
secara online di Tokopedia selama 4 bulan.

\section{Prodedur Penarikan Sampel}

Dalam menentukan sampel, dalam penelitian ini penulis menggunakan metode slovin untuk menentukan berapa besar minimal sampel yang dibutuhkan.

$$
\begin{aligned}
& n=\frac{N}{1+N \cdot e^{2}} \\
& \qquad n=\frac{2,267}{1+2,267 \cdot 0,1^{2}} \\
& \begin{array}{l}
n=95,77 \\
\rightarrow 96 \text { orang. }
\end{array}
\end{aligned}
$$

Keterangan :

$\mathrm{n}$ : Jumlah sampel

$\mathrm{N}$ : Jumlah populasi

e : batas toleransi kesalahan (error tolerance) sebesar $10 \%$

\section{Hipotesis}

Menurut Sugiyono (2017:63), Hipotesis merupakan jawaban sementara terhadap rumusan masalah penelitian, di mana rumusan masalah penelitian telah dinyatakan dalam bentuk kalimat pertanyaan. Penulisan ilmiah ini menggunakan perumusan atas hipotesis untuk membuat pernyataan yang akan mewakili pengaruh Harga, Ulasan dan Tampilan Produk terhadap Keputusan Pembelian yang akan dijabarkan sebagai berikut :

H1 : Diduga Harga berpengaruh terhadap Keputusan Pembelian casing custom dari Rendevous Industries di Tokopedia.
H2 : Diduga Ulasan Produk berpengaruh terhadap Keputusan Pembelian casing custom dari Rendevous Industries di Tokopedia

H3 : Diduga Tampilan Produk berpengaruh terhadap Keputusan Pembelian casing custom dari Rendevous Industries di Tokopedia

H4 : Diduga Harga, Ulasan Produk, dan Tampilan Produk secara simultan berpengaruh terhadap Keputusan Pembelian casing custom dari Rendevous Industries di Tokopedia.

\section{Metode Analisis Data}

Kuesioner

Menurut Sugiyono (2017:142), Kuesioner merupakan teknik pengumpulan data yang dilakukan dengan cara memberi seperangkat pertanyaan atau pernyataan tertulis kepada responden untuk dijawab. Pengumpulan data yang dilakukan oleh peneliti adalah dengan menggunakan kuesioner online. Kuesinoner ini akan disebarkan melalui media sosial seperti WhatsApp dan Email. Responden dapat dengan mudah melakukan pengisian kuesioner dengan cara meng klik alamat website yang tersedia.

\section{SPSS}

SPSS (Statistical Package for the Social Sciences) merupakan suatu software statistik yang banyak digunakan 
dikalangan akademik maupun non akademik. Terdapat dua bagian dalam SPSS ini, yaitu data set dan output. Data set merupakan media untuk menformat dan menginput data, dan bagian output merupakan tampilan hasil dari analisis.

Metode analisis data dalam penelitian kuantitatif ini menggunakan statistik dan dalam pengisian analisis data menggunakan alat bantu SPSS (Statistical Package for the Social Sciences) 24.0 for windows.

\section{Pembahasan dan Hasil Penelitian}

\section{Uji Validitas}

Hasil uji validitas dari kuesioner penelitian digunakan untuk memastikan bahwa kuesioner penelitian disebar telah valid sehingga data yang dihasilkan akutat. Uji validitas dalam penelitian ini dilakukan dengan mengambil sampel sebanyak 96 responden. Perntanyaan di kuesioner dikatakan valida apabila signifikan dari korelasi $<0,05$. Hasil olah data menunjukan bahwa semua peryataan dalam penelitian ini adalah valid karena:

1. Nilai sig pernyataan-pernyataan X1.1-X1.4 : 0,000

2. Nilai sig pernyataan-pernyataan X2.1-X2.4 : 0,000

3. Nilai sig pernyataan-pernyataan X3.1-X3.5 $: 0,000$
4. Nilai sig pernyataan-pernyataan Y1Y9: 0,000

\section{Uji Reliabilitas}

Variabel dalam penelitian ini dikatakan reliabel jika nilai Cronbach's Alpha > 0,6. Hasil pengujian reliabilitas untuk masingmasing variabel adalah sebagai berikut :

1. Nilai Cronbach's Alpha variabel Harga : 0,689

2. Nilai Cronbach's Alpha variabel Ulasan Produk : 0,738

3. Nilai Cronbach's Alpha variabel Tampilan Produk : 0,777

4. Nilai Cronbach's Alpha variabel Keputusan Pembelian : 0,755

Semua variabel dalam penelitian ini dapat dikatakan reliabel karena semua variabel memiliki Cronbach's Alpha lebih dari 0,6.

\section{Uji Normalitas}

Hasil uji normalitas dengan normal probability plot menunjukan bahwa data menyebar di sekitar garis diagonal. Hasil uji Kolmogorov-Smirnov menunjukan nilai signifikansi > 0,0,5 yaitu sebesar 0,082. Dari data yang ada, dapat disimpulkan bahwa residual model regresi berdistribusi normal. 
Tabel 1

Uji Kolmogorov Smirnov

\begin{tabular}{llr}
\hline \multicolumn{3}{c}{ One-Sample Kolmogorov-Smirnov Test } \\
\hline $\mathrm{N}$ & \multicolumn{1}{c}{$\begin{array}{c}\text { Unstandardized } \\
\text { Residual }\end{array}$} \\
\hline Normal Parameters ${ }^{\mathrm{a}, \mathrm{b}}$ & Mean & 96 \\
\cline { 2 - 3 } & Std. Deviation & .0000000 \\
\hline Most Extreme Differences & Absolute & .085 \\
\cline { 2 - 3 } & Positive & .067 \\
\cline { 2 - 3 } & Negative & -.085 \\
\hline Test Statistic & & .085 \\
\hline Asymp. Sig. (2-tailed) & & $.082^{\mathrm{c}}$ \\
\hline
\end{tabular}

(Sumber : Data diolah)

Gambar 1

Normal Probability Plot

Normal P-P Plot of Regression Standardized Residual

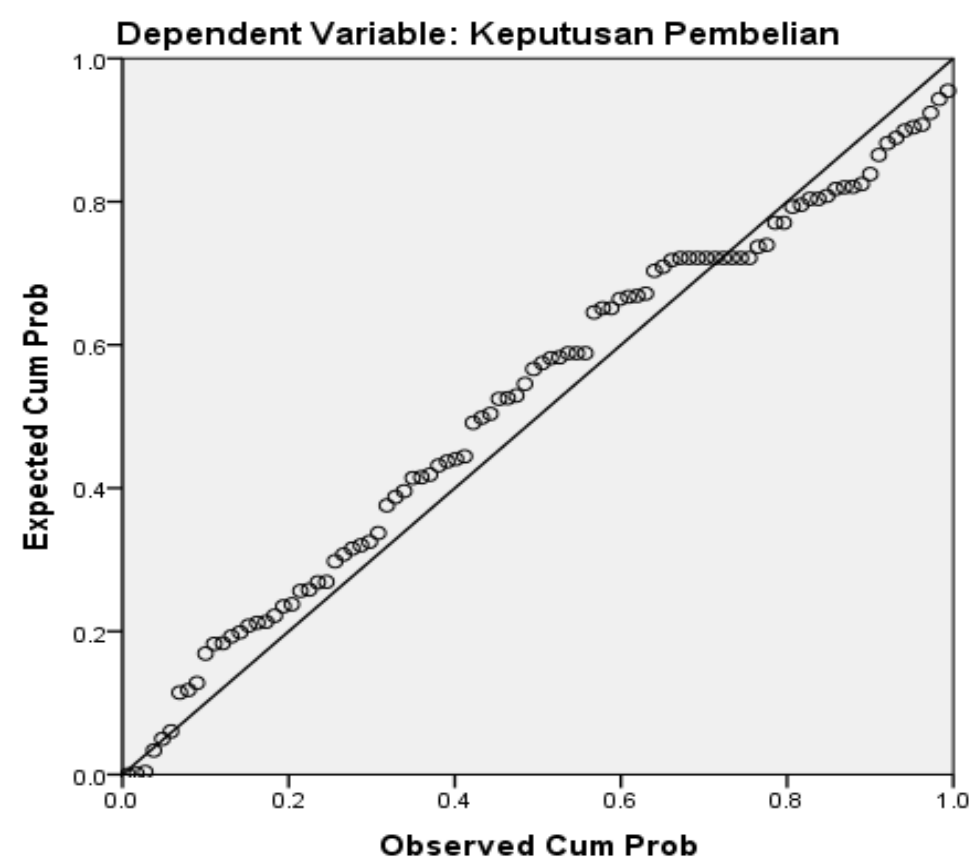

(Sumber : Data diolah) 


\section{Uji Multikolinieritas}

Tabel 2

Hasil Uji Multikolinieritas

\begin{tabular}{|c|c|c|c|c|c|c|c|}
\hline \multirow[b]{3}{*}{ Model } & \multicolumn{5}{|c|}{ Coefficients $^{a}$} & & \\
\hline & \multicolumn{2}{|c|}{$\begin{array}{c}\text { Unstandardized } \\
\text { Coefficients }\end{array}$} & \multirow{2}{*}{$\begin{array}{c}\text { Standardized } \\
\text { Coefficients } \\
\text { Beta }\end{array}$} & \multirow[b]{2}{*}{$\mathrm{t}$} & \multirow[b]{2}{*}{ Sig. } & \multicolumn{2}{|c|}{$\begin{array}{c}\text { Collinearity } \\
\text { Statistics }\end{array}$} \\
\hline & B & Std. Error & & & & $\begin{array}{c}\text { Toleranc } \\
\text { e }\end{array}$ & VIF \\
\hline $1 \quad$ (Constant) & -.596 & 3.784 & & -.157 & .875 & & \\
\hline Harga & .952 & .140 & .499 & 6.797 & .000 & .833 & 1.201 \\
\hline Ulasan Produk & .659 & .187 & .261 & 3.518 & .001 & .817 & 1.224 \\
\hline $\begin{array}{l}\text { Tampilan } \\
\text { Produk }\end{array}$ & .471 & .148 & .254 & 3.180 & .002 & .702 & 1.424 \\
\hline
\end{tabular}

(Sumber : Data diolah)

Gambar 2

Scatterplot

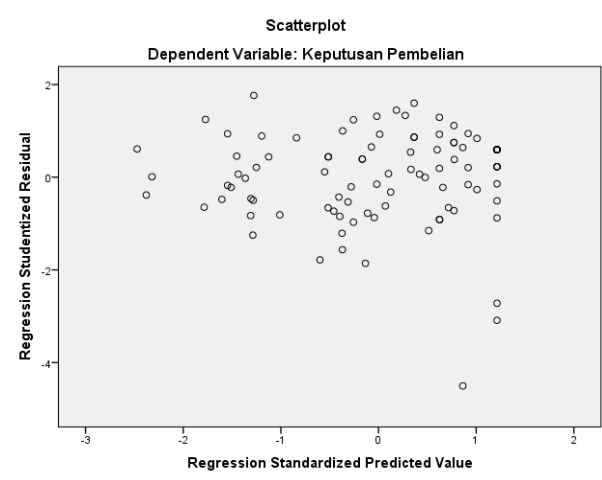

(Sumber : Data diolah)

Berdasarkan tabel 2 dapat dilihat bahwa nilai VIF dan Tolerance untuk masing-masing variabel yaitu Harga, Ulasan Produk dan Tampilan Produk memenuhi syarat yang seharusnya yaitu hasil VIF di bawah 10 dan nilai tolerance $>0,1$. Jadi, dapat disimpulkan bahwa dalam model regresi tidak ada gejala multikolinieritas.

\section{Uji Heteroskedastisitas}

Dari grafik scatterplot di samping, terlihat titik-titik menyebar dan tidak membentuk pola tertentu yang jelas. Dan hasil uji Glejser antara variabel bebas dengan nilai residual. Tabel 3 menunjukan bahwa nilai signifikansi dari variabel bebas semuanya $>0,05$. Sehingga dapat disimpulkan bahwa tidak terjadi masalah heteroskedastisitas dalam model regresi. 
Tabel 3

Hasil Uji Heteroskedastisitas

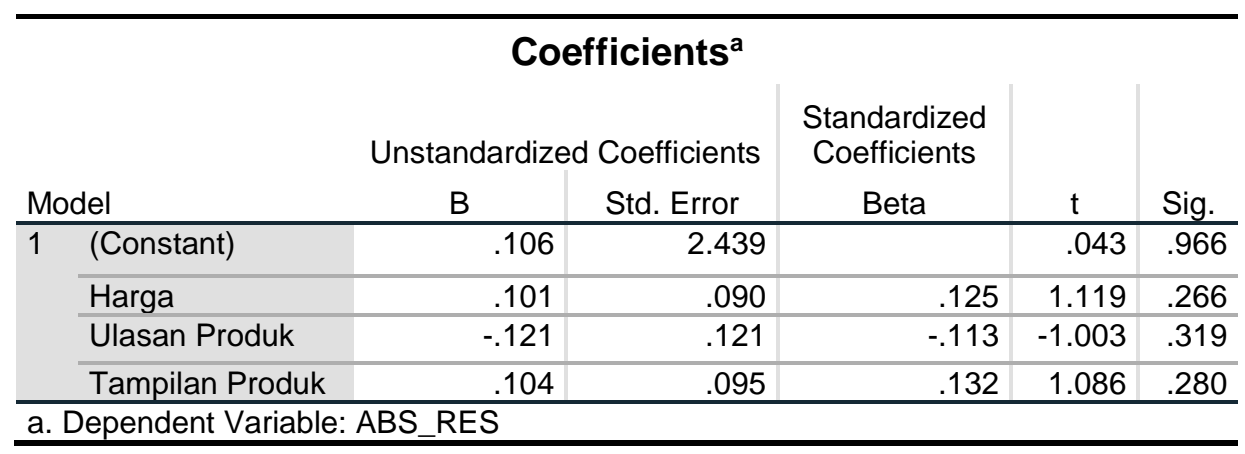

(Sumber : Data diolah)

\section{Analisis Regresi Berganda}

Persamaan regresi yang didapat dalam penelitian ini yaitu :

$Y=-0,596+0,952 X_{1}+0,659 X_{2}+0,471 X_{3}$

Berdasarkan persamaan regresi di atas, dapat dijelaskan bahwa :

1. Konstanta $(\alpha)$ sebesar $-0,595$, menunjukan bahwa apabila harga, ulasan dan tampilan produk bernilai konstan, maka keputusan pembelian akan bernilai negatif yaitu sebesar $-0,595$.

2. Koefisien regresi untuk Harga sebesar 0,952, menunjukan bahwa apabila variabel Harga ditingkatkan, maka akan mengakibatkan peningkatan

3. Keputusan Pembelian sebesar 0,952, dengan asumsi variabel lain konstan.

4. Koefisien regresi untuk Ulasan Produk sebesar 0,659, menunjukan bahwa apabila variabel Ulasan Produk ditingkatkan, maka akan mengakibatkan peningkatan Keputusan Pembelian sebesar 0,659, dengan asumsi variabel lain konstan.

5. Koefisien regresi untuk Tampilan Produk sebesar 0,471, menunjukan bahwa apabila variabel Tampilan Produk ditingkatkan, maka akan mengakibatkan peningkatan Keputusan Pembelian sebesar 0,471, dengan asumsi variabel lain konstan.

\section{Uji F}

Dari tabel 4 diperoleh nilai signifikansi sebesar $0,000<0,05$ sehingga dapat disimpulkan bahwa semua variabel bebas (harga, ulasan produk dan tampilan produk) secara bersama-sama memiliki pengaruh yang signifikan terhadap keputusan pembelian. 


\section{Tabel 4}

\begin{tabular}{llr|r|r|r|r}
\multicolumn{8}{c}{ Hasil Uji F } \\
\hline \multicolumn{7}{c}{ ANOVA $^{\mathbf{a}}$} \\
Model & Sum of Squares & \multicolumn{1}{c}{ df } & Mean Square & \multicolumn{1}{c}{ F } & Sig. \\
\hline 1 & Regression & 991.581 & 3 & 330.527 & 43.670 & $.000^{\mathrm{b}}$ \\
\cline { 2 - 5 } & Residual & 696.325 & 92 & 7.569 & & \\
\hline Total & 1687.906 & 95 & & & \\
\hline
\end{tabular}

a. Dependent Variable: Keputusan Pembelian

b. Predictors: (Constant), Tampilan Produk, Harga, Ulasan Produk

(Sumber : Data diolah)

\section{Uji t}

\section{Tabel 5}

\section{Hasil Uji t}

\begin{tabular}{lrrr}
\hline \multicolumn{1}{c}{ Model Anova } & t tabel & \multicolumn{1}{c}{ t hitung } & \multicolumn{1}{c}{ Sig. } \\
& & & \\
\hline Harga & 1.986 & 6.797 & 0.000 \\
\hline Ulasan Produk & 1.986 & 3.518 & 0.001 \\
\hline Tampilan Produk & 1.986 & 3.180 & 0.002 \\
\hline a. Dependent Variable: Keputusan Pembelian & & & \\
\hline
\end{tabular}

(Sumber : Data diolah)

Dari tabel 5, hasil analisis uji t yang diperoleh adalah sebagai berikut :

1. Harga perpengaruh positif dan signifikan terhadap keputusan pembelian produk casing custom Rendevous Industries di Tokopedia

2. Ulasan produk perpengaruh positif dan signifikan terhadap keputusan pembelian produk casing custom Rendevous Industries di Tokopedia

3. Tampilan produk perpengaruh positif dan signifikan terhadap keputusan pembelian produk casing custom Rendevous Industries di Tokopedia

\section{Koefisien Determinasi $\left(R^{2}\right)$}

Dari tabel 6, dapat dilihat nilai dari koefisien determinasi $\left(\mathrm{R}^{2}\right) /$ Adjusted $R$ Square adalah sebesar 0,574.Hal ini menunjukan bahwa kemampuan variabel Harga (X1), Ulasan Produk (X2) dan Tampilan Produk (X3) memiliki pengaruh terhadap keputusan pembelian (Y) sebesar $57,4 \%$, sedangkan $42,6 \%$ sisanya merupakan pengaruh dari variabel bebas lainya yang tidak diteliti. 


\section{Tabel 6}

\section{Hasil Koefisien Determinasi}

\begin{tabular}{lc|c|c|c}
\hline & \multicolumn{4}{c}{ Model Summary } \\
Model & $\mathrm{R}$ & $\mathrm{R}$ Square & $\begin{array}{c}\text { Adjusted R } \\
\text { Square }\end{array}$ & $\begin{array}{c}\text { Std. Error of the } \\
\text { Estimate }\end{array}$ \\
\hline 1 & $.766^{\mathrm{a}}$ & .587 & .574 & 2.751 \\
\hline a. Predictors: (Constant), Tampilan Produk, Harga, Ulasan Produk
\end{tabular}

(Sumber : Data diolah)

\section{Kesimpulan dan Saran}

\section{Kesimpulan}

Berdasarkan dengan hasil penelitian dan pembahasan yang ada, maka kesimpulan yang dapat ditarik adalah sebagai berikut :

1. Harga berpengaruh positif dan signifikan terhadap keputusan pembelian produk casing custom Rendevous Industries di Tokopedia

2. Ulasan produk perpengaruh positif dan signifikan terhadap keputusan pembelian produk casing custom Rendevous Industries di Tokopedia

3. Tampilan produk perpengaruh positif dan signifikan terhadap keputusan pembelian produk casing custom Rendevous Industries di Tokopedia

4. Harga, ulasan produk dan tampilan produk secara simultan berpengaruh terhadap keputusan pembelian produk casing custom Rendevous Industries di Tokopedia

\section{Saran}

1. Berdasarkan dari analisis variabel Harga pada indikator pernyataan kuesioner X1.4. Harga casing custom Rendevous Industries relative lebih murah dari harga produsen lain, menunjukan nilai ratarata paling kecil diantara indikator Harga lainnya yaitu 4,21. Terdapat 2 responden yang menyatakan Sangat Tidak Setuju dan terdapat 3 responden menyatakan Tidak Setuju. Dari hal-hal demikian dapat disarankan kepada pihak Rendevous Industries agar menurunkan sedikit harga jual dan melakukan lebih banyak program diskon atau gratis ongkos kirim pada pelanggan tanpa harus membeli dalam kuantitas banyak. Hal ini disarankan agar semakin banyak orang yang tertarik untuk membeli produk custom casing di Rendevous Industries.

2. Berdasarkan dari analisis variabel Tampilan Produk pada indikator pernyataan kuesioner X3.4. Varian tipe casing handphone yang ditawarkan lengkap, menunjukan nilai rata-rata paling kecil diantara indikator Tampilan Produk lainnya yaitu 4,58. Terdapat 1 responden 
yang menyatakan Sangat Tidak Setuju. Dari hal-hal demikian dapat disarankan kepada pihak Rendevous Industries agar menambah varian tipe casing handphone dan meningkatkan tampilan produknya dengan mengambil gambar produk dengan fotogragfer yang handal, serta menampilkan keunikan yang dimiliki. Hal ini disarankan agar semakin banyak orang yang tertarik untuk membeli produk custom casing di Rendevous Industries.

\section{Daftar Pustaka}

Alma, B. (2011). Manajemen Pemasaran dan Pemasaran Jasa. Bandung: Alfabeta.

Alma, B. (2014). Manajemen Pemasaran Dan Pemasaran Jasa. Bandung: Alfabeta.

Databoks. (2018). Tokopedia Tetap Memimpin Jumlah Pengunjung e-Commerce TW III 2018 | Databoks. Diambil 13 Agustus 2019 , website: https://databoks.katadata.co.id/datapubl ish/2018/10/22/tokopedia-tetapmemimpin-jumlah-pengunjung-ecommerce-tw-iii-2018

Fauziah, U. U., Eldine, A., \& Sume, S. A. (2019). Sales Promotion Dan Harga Terhadap Volume Penjualan. Jurnal Ilmu Manajemen, 2(1), 16.

Idris, M. 2017. Tokopedia Raup Rp 1 Triliun Tiap Bulan. Diambil 13 Agustus 2019, dari Detikinet website: https://inet.detik.com/business/d3585265/tokopedia-raup-rp-1-triliuntiap-bulan

Internetworldstats.com. (2019). Internet Top 20 Countries-Internet Users 2019. Diambil 13 Agustus 2019, dari https://www.internetworldstats.co $\mathrm{m} /$ top20.htm

Kotler, P., \& Amstrong, G. (2012). Prinsip-Prinsip Pemasaran (13 ed.). Jakarta: Erlangga.

Kotler, P., \& Amstrong, G. (2015). Principle of Marketing (15 ed.). London: Pearson Education.

Lackermair, G., Kailer, D., \& Kanmaz, K. (2013). Importance of Online Product Reviews from a Consumer's Perspective. Advances in Economics and Business, 1(1), 5.

Presidenri.go.id. (2016, Mei). Membuka dan Mengembangkan Potensi ECommerce di Indonesia | Presiden Republik Indonesia. Diambil 16 Januari 2019, dari http://presidenri.go.id/beritaaktual/membuka-danmengembangkan-potensi-ecommerce-di-indonesia.html

Pudjihardjo, M. C., \& Wijaya, H. (2015). Analisa Pengaruh Kepercayaan, Kemudahan, Kualitas Informasi, Dan Tampilan Produk Terhadap Keputusan Pembelian Melalui Pemasaran Di Media Sosial (Studi Pada Pengguna Media Sosial Di Shapeharve). 16.

Setiaji, P. (2013). Sistem Pendukung Keputusan Dengan Metode Simple Additive Weighting. Simetris: Jurnal Teknik Mesin, Elektro dan Ilmu Komputer, 1(1), 59. https://doi.org/10.24176/simet.v1i 1.117

Shanthi, R., \& Kannaiah, D. (2015). Consumers' Perception on Online Shopping. International Peer- 
reviewed Journal, 13. Diambil dari http://researchonline.jcu.edu.au/39753/ 1/Dr.\%20Desti\% 20Consumers $\% 20$ perception $\% 20$ on $\% 2$ 0Online\%20Shop ping.pdf

Sinha, J., \& Kim, J. (2012). Factors affecting Indian consumers' online buying behavior. Innovative Marketing, 8(2), 13.

Sudarsono, B. (2017). Goldmerchant Sebagai Alat Promosi Dalam Meningkatkan Penjualan Produk Studi Kasus: Member Tokopedia. 2, 10.
Sudaryono. (2016). Manajemen Pemasaran, Teori Dan Implementasi (1 ed.). Yogyakarta: ANDI.

Sugiyono. (2017). Metode Penelitian Kuantitatif, Kualitatif dan $R \& D$. Bandung: Alfabeta.

Sunyoto, D. (2014). Konsep dasar riset pemasaran dan perilaku konsumen. Yogyakarta: CAPS. 